\title{
Exploring the Relationship Between Business Model Innovation, Corporate Sustainability, and Organisational Values within the Fashion Industry
}

\author{
Pedersen, Esben Rahbek Gjerdrum ; Gwozdz, Wencke; Hvass, Kerli Kant
}

Document Version

Accepted author manuscript

Published in:

Journal of Business Ethics

DOI:

$10.1007 / \mathrm{s} 10551-016-3044-7$

Publication date:

2018

License

Unspecified

Citation for published version (APA):

Pedersen, E. R. G., Gwozdz, W. \& Hvass, K. K. (2018). Exploring the Relationship Between Business Model Innovation, Corporate Sustainability, and Organisational Values within the Fashion Industry. Journal of Business Ethics, 149(2), 267-284. https://doi.org/10.1007/s10551-016-3044-7

Link to publication in CBS Research Portal

\section{General rights}

Copyright and moral rights for the publications made accessible in the public portal are retained by the authors and/or other copyright owners and it is a condition of accessing publications that users recognise and abide by the legal requirements associated with these rights.

\section{Take down policy}

If you believe that this document breaches copyright please contact us (research.lib@cbs.dk) providing details, and we will remove access to the work immediately and investigate your claim.

Download date: 26. Apr. 2023 


\section{Exploring the Relationship Between Business Model Innovation, Corporate Sustainability, and Organisational Values within the Fashion Industry}

\section{Esben Rahbek Gjerdrum Pedersen, Wencke Gwozdz, and Kerli Kant Hvass}

Journal article (Post print version)

CITE: Exploring the Relationship Between Business Model Innovation, Corporate Sustainability, and Organisational Values within the Fashion Industry. / Gjerdrum Pedersen, Esben Rahbek; Gwozdz, Wencke; Hvass, Kerli Kant. In: Journal of Business Ethics, २०16.

The final publication is available at Springer via http://dx.doi.org/10.1007/s10551-016-3044-7

Uploaded to Research@CBS: October २016 
Research Paper:

\title{
Exploring the Relationship between Business Model
}

\section{Innovation, Corporate Sustainability, and Organisational}

\section{Values}

\author{
Esben Rahbek Gjerdrum Pedersen • Wencke Gwozdz • Kerli Kant Hvass \\ Copenhagen Business School Centre for Corporate Social Responsibility (cbsCSR)
}

\begin{abstract}
The objective of this paper is to examine the relationship between business model innovation, corporate sustainability, and the underlying organisational values. Moreover, the paper examines how the three dimensions correlate with corporate financial performance. It is concluded that companies with innovative business models are more likely to address corporate sustainability and that business model innovation and corporate sustainability alike is typically found in organisations rooted in values of flexibility and discretion. Business model innovation and corporate sustainability thus seem to have their origin in the fundamental principles guiding the organisation. In addition, the study also finds a positive relationship between the core organisational values and financial performance. The analysis of the paper is based on survey responses from 492 managers within the Swedish fashion industry.
\end{abstract}

Key words: Business model innovation, Corporate sustainability, Corporate social responsibility (CSR), Organisational values, Financial Performance.

\section{Published in:}

Journal of Business Ethics, DOI: 10.1007/s10551-016-3044-7 


\section{Introduction: The Call for Sustainable Business Models}

Until recently, the business model literature paid only limited attention to the social and environmental challenges facing the world today. Focus was on market sustainability rather than social sustainability and environmental sustainability (Schaltegger et al., 2011). For instance, Stubbs and Cocklin (2008, p. 103) argued that the: “(..) understanding of sustainable business models and how sustainable development is operationalized in firms is weak (...)". Likewise, Lüdeke-Freund (2009, p. 11) argued that the literature is still to tackle: “(..) the intersections of business models and corporate sustainability". In recent years, however, there has been a growing interest in integrating corporate sustainability into conventional business model thinking (Schaltegger et al., 2015). Concepts like social business models (Yunus et al., 2010), green business models (Sommer, 2012), triple bottom line business models (Osterwalder and Pigneur, 2010), community development business models (Stubbs and Cocklin, 2008), inclusive business models (Michelini and Fiorentino, 2012), and sustainability business models (Stubbs and Cocklin, 2008; Birkin et al., 2009) have all been introduced to describe new business logics that benefit both business and society. Moreover, special issues on sustainable business models are beginning to appear in international academic journals addressing corporate sustainability and responsibility, e.g. Journal of Cleaner Production (2013) and Organization E Environment (2015).

The objective of this paper is to examine the relationship between business model innovation and corporate sustainability, the mediating influence of organisational values, and the effect on corporate financial performance. There is a rich, varied literature on examining the role of 
various internal (organisational culture, management style, organisational structure etc.) and external factors (stakeholder pressures, environmental uncertainty, national culture etc.) in explaining corporate sustainability and other related concepts (corporate social responsibility, corporate citizenship etc.) (See e.g. Aragón-Correa and Sharma, 2003; Buysse and Verbeke, 2003; Clemens et al., 2008; Menguc et al., 2010; Rueda-Manzanares et al., 2008). However, less has been done to study whether and how the dominant business logic of an organisation is associated with corporate sustainability and financial performance. The underlying assumption is that business model innovation and corporate sustainability are related, as these types of organisational changes call for similar resources and capabilities. Moreover, it is expected that business model innovation as well as corporate sustainability is linked to the fundamental values/principles underpinning the organisation (Denison and Spreitzer, 1991).

The paper contributes to the emerging academic debate regarding the relationship between business model innovation and corporate sustainability as well as the underlying drivers and consequences. Corporate sustainability is often dealt with as a distinct type of innovation, where there is less emphasis on exploring the linkages between the overall innovative capacity of an organisation and the specific level of activity regarding corporate sustainability (Boons and Lüdeke-Freund, 2013; Louche et al., 2010). From a practitioner perspective, the results from the paper attempt to shed more light on when and how a company's business model is in sync with its sustainability mindset and the underlying organisational values. The point is not that some companies should ignore social and environmental investments. However, it may be so 
that certain business model configurations make it easier for a company to address the sustainability challenges.

The empirical focus of this paper is on the fashion industry which is well-documented for having significant social and environmental impacts. The production of cotton for instance uses extensive quantities of both pesticides and water, making it one of the world's most polluting crops (Giesen, 2008). Over the last few decades we have seen a large number of prominent fashion companies being criticised by the media, NGOs and other stakeholders for poor social and environmental performance (Pedersen and Gwozdz, 2014). However, despite these criticisms, the fashion industry has also been among the frontrunners when it comes to new sustainability initiatives. For instance, apparel and footwear companies were among the first organisations to formulate supplier codes of conduct in the early 1990s. Today, we are also seeing how a number of fashion companies have introduced new sustainability initiatives which challenge the conventional business models within the industry, whether it concerns new resources (e.g. new textile fibres) or new revenue channels (e.g. clothes leasing). As an example, a number of fashion brands have, individually or in partnership with other organisations, introduced various take-back, resell, reuse, and recycle programmes (e.g. Marks \& Spencer, Patagonia, Levi's, Bestseller, and H\&M). Although the scalability of some of these initiatives can be challenged, there is little doubt that a number of fashion companies are experimenting with new business models to tackle the sustainability challenges. Therefore, the fashion industry is in many ways an ideal industry to explore the linkages between business models and sustainability. 
This paper begins with a short review of the business model construct and the formulation of relevant hypotheses. The context is then presented through a short presentation of the fashion industry and some of the recent business model innovations within this sector. In the methodology section, we describe how we operationalized the concepts, designed the survey, and analysed the data. This is followed by the results from our study and a discussion of the implications for both research and practice. Finally, in the conclusion we revisit the main findings from the analysis, reflect on their limitations and propose future avenues for research that studies the intersections between business models and sustainability.

\section{Literature Review}

\section{Business Models and Business Model Innovation}

Business model thinking is fast becoming a mainstream concept in both academia and practice. In general, we define a business model as the: “(...) the rationale of how an organization creates, delivers, and captures value" (Osterwalder and Pigneur, 2010, p. 14). The business model concept emerged during the dotcom boom in the 1990s, when new internet start-ups with gamechanging technologies began challenging conventional bricks-and-mortar industries (Boons and Lüdeke-Freund, 2013). However, the concept was quickly integrated in mainstream business language and is today used across industries as a popular way to describe, analyse and communicate the architecture of an organisation. The growing popularity of the business model concept is also reflected in academia where there has been as rapid growth in publications addressing business models from a variety of perspectives (Zott et al., 2011). From its inception, 
the business model literature has been interdisciplinary in nature and has found inspiration from a plethora of theoretical sources, which has occasionally led to calls for the development of a more solid theoretical foundation (Morris et al., 2005; Zott et al., 2011; Mitchell and Coles, 2004; Teece, 2010)

Despite its popularity, the business model concept is still characterised by an element of definitional ambiguity. The term 'business model' is used frequently in both academia and business, but it is generally acknowledged that there are multiple definitions for this term (Brettel et al., 2012; Dahan et al., 2010; Morris et al., 2005; Osterwalder and Pigneur, 2010). The challenge is that the term 'business model' is a multidimensional construct that cuts across several academic disciplines and functional areas and cannot easily be captured in a single, allencompassing definition. Despite this 'fuzziness', the concept of 'value' plays a pivotal role in most discussions on the fundamental characteristics of a business model. Central in business model thinking is how organizations capture, create and deliver value (Chesbrough, 2007; Johnson et al., 2008; Osterwalder and Pigneur, 2010; Roome and Louche, 2015). The mainstream business model literature has historically focused on value from the perspective of the customer and the company, whereas there has been less focus on value for a broader set of stakeholders.

The importance of value in business model thinking is also manifested in the various models, which outline the main building blocks of a business model (see e.g. Brettel et al., 2012; Kiron et al. 2013; Morris et al., 2005; Osterwalder, 2004). For instance, Johnson et al. (2008) discusses four elements in a business model: customer value proposition, profit formula, key resources, and key processes. Moreover, Hamel (2000) distinguishes between core strategy, strategic resources, 
customer interface, and value network. Finally, Osterwalder \& Pigneur (2010) have become popular exponents of business model thinking by developing a business model canvas comprising nine basic building blocks (Customer segments, Value proposition, Channels, Customer relationships, Revenue streams, Key resources, Key activities, Key partnerships, and Cost structure).

Related to the concept of the business model is business model innovation which has experienced a growing interest in recent years (Aspara et al., 2010; Spieth et al., 2014). Business model innovation is essentially about developing new ways to capture, create and deliver value and moves beyond more narrowly defined categories, such as product, service, and process innovation (Preuss, 2011; Wells, 2008). Business model innovation can be important to the success of an organisation as well as a valuable organisational capability (Aspara et al., 2010; Lindgardt et al. 2009; Chesbrough, 2010; Amit and Zott, 2012). Failing to be innovative implies that competitors will enter the scene with new offerings that makes prevailing business models redundant (Chesbrough, 2010; Schlegelmilch et al., 2003; Osterwalder and Pigneur, 2010). A distinguishing character of business model innovation is that it cannot be reduced to, for example, a technological innovation but concerns the entire 'architecture' of a company (Teece, 2010). The value of a new technology depends on how it is produced, priced, and distributed it.. To quote Chesbrough (2010, p. 354): “Technology by itself has no single objective value. The economic value of a technology remains latent until it is commercialized in some way via a business model". 
A continuum exists between minor, incremental improvements of existing business models to more radical advances that fundamentally challenge predominant business models within the industry (Davenport et al., 2006; Schaltegger et al., 2011). For instance, the introduction of a new green product line is likely to be considered as an incremental innovation whereas a total transformation of the organisation from an asset- to an access-based business model is an example of a more radical innovation (Keskin et al., 2013; Bardhi and Eckhardt, 2012). Lindgren and Taran (2011, p. 232) have proposed a model which outlines the main differences between the two types of business model innovation. Incremental business model innovation involves continuous improvements of existing offerings without major changes in internal competences and external partner relationships, whereas radical business model innovation involves new types of offerings and the redesign of existing organisational characteristics and stakeholder networks (Ibid.). However, incremental and radical business model innovation represents two ends of a continuum between which a number of combinations can be observed.

\section{The Inclusion of Corporate Sustainability in Conventional Business Model Thinking}

In recent years, discussions on corporate sustainability perspectives are finding their way into business models. Corporate sustainability in this context can be understood broadly as: “(...) meeting the needs of the firm's direct and indirect stakeholders (such as shareholders, employees, clients, pressure groups, communities etc.), without compromising its ability to meet the needs of future stakeholders as well. Towards this goal, firms have to maintain and grow their economic, social and 
environmental capital base while actively contributing to sustainability in the political domain" (Dyllick and Hockerts, 2003, p. 131). In line with this definition, corporate sustainability perspectives on business models often depart from a critique of the conventional business model thinking, which is seen as being too narrow and simplistic when it comes to boundaries and focus. As noted by Bocken et al., 2015, p. 70):

"Business models are often perceived from a value creation perspective that focuses on satisfying customer needs, economic return and compliance. For sustainability thinking, this focus is too narrow and raises the need for a more holistic view of value that integrates social and environmental goals, to ensure balancing or ideally alignment of all stakeholder interests to deliver "sustainable value" creation".

The emerging literature on sustainable business models shares a number of common characteristics. For instance, the literature has identified a common frame of reference in stakeholder theory, which has played a pivotal role in corporate sustainability discussions over the past decades (Freeman and McVea, 2001; Parmar et al., 2010). While mainstream business model thinking tends to give primacy to customers, corporate sustainability literature expands the organisational boundaries to include a wider set of stakeholders (e.g. non-governmental organisations, local communities, and the environment). In the words of Schaltegger et al. (2015, forthcoming): “(...) a business that contributes to sustainable development needs to create value to the whole range of stakeholders and the natural environment, beyond customers and stakeholders". Another distinguishing character is the move from a single (financial) bottom line toward to triple bottom line perspective, which means that business models move from being the logic for 
making money to becoming a logic for creating economic, social and environmental value for all relevant stakeholders (Joyce et al., 2015). To give a concrete example, Stubbs and Cocklin (2008) broadened the focus of the business model and integrated business model and corporate sustainability thinking, where the purpose of the firm was to cover economic, social as well as environmental dimensions and take into account the needs and wants of all stakeholders. This perspective is echoed in more recent attempts to redefine the value construct in the business model thinking to capture value exchanges for stakeholders, society and the natural environment (Abdelkafi and Täuscher, 2015; Bocken et al., 2014, 2015). Moreover, existing emphasis on value creation, value delivery and value capture is now broadened to cover value destroyed (e.g. negative social impacts) and value missed (e. under-utilised resources) for individuals, organisations, networks, and systems (Bocken et al., 2013; Joyce et al., 2015; Upward and Jones (2015). Therefore, from a sustainability perspective the narrow view of value in business model thinking is expanded to approximate the broader concept of impact.

The critique of conventional business model thinking has led to the development of alternative models, which better capture stakeholder theory and triple bottom line thinking. For instance, Osterwalder and Pigneur (2010) argue that sustainability could be integrated in conventional business model thinking by adding social costs and benefits. Lüdeke-Freund (2009) also proposes an extended business model, which address non-market factors, e.g. the positive and negative externalities from the business model on the wider society and the environment. Bocken (2013) takes an alternative approach by suggesting that the value proposition of the conventional business model canvas should be divided into society, environment and the 
economy. Most recently, a triple-layered business model has been proposed by Joyce et al. (2015) which add an environmental life cycle canvas and a social stakeholder canvas to the conventional (economic) business model canvas. While the above-mentioned alternatives highlight gaps in current business model thinking, they also seem to acknowledge the fundamental business model components proposed by Osterwalder and Pigneur (2010).

\section{The Relationship between Corporate Sustainability and Business Model Innovation}

Corporate sustainability has also permeated discussions of business model innovation. Scholars and practitioners alike increasingly recognize the value creating potential of business models to generate positive or eliminate negative societal impacts (Bocken et al., 2014; Hall and Wagner, 2012; Nidumolu et al., 2009; Sharma and Henriques, 2005). The concept of sustainable business model innovation reflects this view by acknowledging a broader set of stakeholders and integrating triple bottom line thinking in the business model. Formally, sustainable business model innovation can be defined as: "(...) innovation to the way business is done by creating a competitive advantage through superior customer value while contributing positively to the company, society, and environment while minimizing harm" (Bocken et al., 2015, p. 68). Sustainable business model innovation is not an entirely new phenomenon, as various types of innovative approaches to corporate sustainability have been addressed under various headings such as: sustainability innovation, CSR innovation, systemic CSR, eco-innovation, cleaner production, sustainable entrepreneurship, cradle-to-cradle, cleantech, sustainable entrepreneurship, product service systems and collaborative consumption. (see e.g. Bocken, 2015; Klewitz and 
Hansen, 2014; Louche et al., 2010; Preuss, 2011; Adams et al., 2015). Seelos and Mair, 2005, 2007; Visser, 2010; Johnson and Suskewicz, 2009).

Although corporate sustainability can be an important component in business model innovation, it is worth noting that companies with sustainability activities are not innovative per se just as innovative companies are not automatically sustainable. Evidence indicates that the dominant approach to corporate sustainability is conformity rather than opportunity-seeking (Pedersen and Gwozdz, 2014). For instance, a company adopting a corporate sustainability standard (Global Compact, Global Reporting Initiative etc.) is not necessarily innovative, and neither is a company experimenting with new revenue channels necessarily effective at corporate sustainability. Therefore, the concepts of business model innovation and corporate sustainability are distinct in theory and practice although they merge in cases of sustainable business model innovation, which can be seen as an advanced form of corporate sustainability (Halme and Laurila, 2009).

It is likely, though, that in terms of implementation, business model innovation and corporate sustainability share a number of common threads. . At least, there are striking similarities between the two streams of literature when it comes to internal barriers and success factors, which highlight the fact that innovation as well as corporate sustainability is very much about change. Commitment to corporate sustainability necessitates a transformation of existing business practices. As a result, new business models become difficult to realise in organizations that favour stability over change (Schaltegger et al., 2011; Haanaes et al., 2012). Therefore, we hypothesize that comprehensive sustainability efforts are more likely to take place in 
organizations that demonstrate high levels of business model innovation (Hypothesis 1). The point is not that business model innovation automatically initiates comprehensive sustainability activities (or vice versa), but rather it is suggested that companies with innovative business models possess resources and capabilities which facilitate the adoption of proactive corporate sustainability strategies.

Hypothesis 1: Companies demonstrating high levels of business model innovation will also demonstrate high levels of corporate sustainability.

At the most fundamental level, we hypothesize that business model innovation and corporate sustainability call for similar organisational values (Hypothesis 2). The transformational nature of business model innovation and corporate sustainability is difficult to accomplish in organisations relying heavily on formal rules and procedures while downplaying creativity and out-of-the-box thinking (Prajogo and McDermott, 2011). For instance, a culture allowing organization members to question existing norms, rules, and routines has been identified as an important precondition for business model innovation, which often break with the prevailing mindset and business models (Johnson et al., 2008, Schlegelmilch et al., 2003). Similarly, Abdelkafi and Täuscher (2015) stress that sustainability necessitates a transformation of the dominant business logic which is unlikely to happen in organisations dominated by stability and continuity. Overall, the corporate sustainability literature over the years highlighted a diverse set of internal characteristics that influence organisational approaches to sustainability, including creativity, open dialogue, debate, experimentation, and learning (Hahn and AragónCorrea, 2015; Medeiros et al., 2014). While these dimensions arguably differ, they all circle 
around the propensity toward fundamental organisational traits regarding learning, adaptation and flexibility. In sum, we hypothesize the following:

Hypothesis 2: Companies with organisational values characterised by flexibility and discretion are more likely to demonstrate high levels of business model innovation and corporate sustainability.

\section{Business Model Innovation, Corporate Sustainability and Performance}

A substantial amount of research assumes a number of positive benefits from innovation (first mover advantages, adaptation to market uncertainties, improved stakeholder relationships etc.), which can be expected to influence the bottom line (Busch et al., 2011). In relation to business models, the results from a decade-long study of 100 companies indicate that continued business model innovation improve the competitive position and financial results (Mitchell and Coles, 2004). Likewise, a survey among 765 CEOs concluded that financial outperformers put twice as much emphasis on business model innovation compared to underperformers (IBM, 2006). The literature on corporate sustainability also ascribes a number of internal and external benefits to social and environmental initiatives (such as enhanced image, better customer relationships, improved efficiency, reduced risks of fines and lawsuits etc.) which can eventually be expected to have a positive impact on the bottom line (see e.g. Branco and Rodrigues, 2006; Weber, 2008). This result is also echoed in a number of management surveys (Carroll \& Shabana, 2010; Lee, 2008). For instance, a survey by McKinsey concluded that 76 percent of executives believe that sustainability creates long-term shareholder value (McKinsey, 
2010a). In a similar vein, a global study conducted by Accenture report that 93 percent of CEOs consider sustainability as critical for the future success of their companies (Accenture, 2010).

Although business model innovation is often treated as a positive organisational trait, innovation may come with a cost (higher R\&D costs, product failures, employee turnover etc.) with the net result that it is sometimes more attractive to adopt a follower strategy (Aspara et al., 2010; Naranjo-Valencia et al., 2011; Simpson et al., 2006). Therefore, in some cases business model innovation may result in lower financial performance (Aspara et al., 2010). Looking at corporate sustainability, there are decades of inconclusive evidence regarding the relationship between corporate social performance (CSP) and corporate financial performance (CFP), and a great deal of conceptual and methodological debate exists regarding the proper meaning and measurement of these concepts (Busch et al., 2011; Carroll and Shabana, 2010; Margolis and Walsh, 2003; Vogel, 2005). Even though most studies report a positive relationship between CSP-CFP, it is still surrounded by considerable uncertainty if, when, and how corporate sustainability pays off (Margolis and Walsh, 2003; Orlitzsky et al, 2003; Surroca et al., 2010). Therefore, the relationship between business model innovation and corporate sustainability on financial performance may be more complex and less straightforward than assumed.

However, based on the mainstream literature of business model innovation and corporate sustainability alike, it is reasonable to assume a business case for both business model innovation and corporate sustainability. As for business model innovation, evidence from a global CEO survey indicates that companies emphasising business model innovation yield higher operational margins (IBM, 2006). By changing the architecture of business, for example 
forming new strategic partnerships, the company can reduce costs, improve flexibility, and exploit new market opportunities (Ibid.). The conclusion is supported by Amit and Zott (2008) who conclude that companies with novelty-centered business models under some conditions demonstrate higher firm performance. The ability to innovative is not least important in the fashion industry which is infamous of fast-changing styles, quick turnaround times, and flexible manufacturing systems (Fletcher, 2008; Fletcher and Grose, 2012). As for corporate sustainability, it is suggested that social and environmental initiatives can be instrumental in improving stakeholder satisfaction and building intangible assets (e.g. reputation) which will eventually influence financial performance (Orlitzsky et al. 2003; Surroca et al., 2010). This hypothesis is also in line with a recent survey which indicates that companies are more likely to gain profits from sustainability if several business model components are changed (Kiron et al. 2013). Therefore, we propose the following hypothesis:

Hypothesis 3: There is a positive relationship between the level of business model innovation as well as sustainability performance and corporate financial performance.

\section{Context: The Fashion Industry and the Emergence of Sustainability Business Models}

The fashion industry has evolved from artisan tailors to multinational global corporations, spread over different departments, locations, countries, and continents, while the manufacturing process has largely remained the same. (Hilger, 2008). The fashion industry today is highly complex and characterised by very long and global supply chains with a large 
number of agents (Dickson et al., 2012; Kozlowki et al., 2012). Moreover, globalisation and new communication technologies have implied that fashion has become faster and less expensive (Black, 2010). Speed and change have become synonyms with the fashion industry and companies' survival is determined by flexibility and quick responsiveness (Christopher et al., 2004).

The current fashion industry with extensive use of resources, short product life-cycles, and over-consumption are generating a large number of negative societal impacts. The major environmental challenges are associated with excessive use of water, pesticides, chemicals, and energy during the different phases of the fashion supply chain (Allwood et al., 2006). Social problems includes unfair labour practices such as child labour, low salaries, and occupational health issues due to price pressures and labour intensive manufacturing (Ibid.). The long, complex supply chains also limits transparency and visibility, which makes it difficult for consumers and other stakeholders to know where the garments come from and how they are produced (Pedersen and Andersen, 2015). However, the challenges are not only associated with the upstream supply chain. The downstream activities related to consumers' buying, using and disposal behaviour also have considerable environmental impacts (Hvass, 2014; Pedersen and Andersen, 2015). The availability of cheap, low quality clothes has increased consumption resulting in a throwaway fashion culture (also called fast fashion) (Fletcher, 2008; Moore and Birtwistle, 2004). Studies show that over 90 million items of clothing end up in landfills globally each year and in the UK alone consumers produce yearly 1.5 - 2 million tons of textile waste of which 1.2 tons end in landfills (DEFRA, 2007). 
Many fashion companies are trying to address the negative social and environmental impacts by getting better control over their supply chain. For instance, a large number of fashion brands are adopting standards and are introducing codes and conduct to better manage the social and environmental dimensions of the supply chain (Ashby et al., 2013). Moreover, new materials and processing techniques are introduced to lower the environmental impacts. Examples include Levi's Water $<$ Less $^{\mathrm{TM}}$ jeans and Puma's InCycle ${ }^{\mathrm{TM}}$ line of biodegradable or recyclable products. Established fashions brands and retailers have also experimented with new types of recycling, reusing or reselling alongside their conventional, possession-based business models. For instance, Marks and Spencer has collaborated with Oxfam on collecting discarded clothes and transforming them into new garments (Morgan, 2015). Moreover, Swedish Filippa K and American Eileen Fisher are offering customers an opportunity to bring back used garments, which they resell through second-hand stores (Hvass, 2014, 2015). Moreover, online resell business models are also emerging which provides a channel for consumers to resell their used clothing. A good example is outdoor company Patagonia's online resell platform in collaboration with eBay.

There are also companies which have created entire business models to address the negative impacts of the conventional fashion industry. An example is upcycling companies, which convert pre- or post-consumer waste into new garments (e.g. Junky Styling, Worn Again, From Somewhere, and Globe Hope) (see. e.g. Cassidy and Han, 2013; Pedersen and Andersen, 2015). Moreover, new types of leasing, sharing and swapping have emerged based on current market trends towards collaborative consumption (Botsman and Rogers, 2010). As an example, a 
number of clothing libraries have emerged which offer consumers a fee-based opportunity to share an extended wardrobe (Pedersen and Netter, 2015). In addition, there are attempts to rediscover local manufacturing and local materials as a response to the drawbacks from the long, global supply chains.

\section{Methodology}

\section{Sample and Data Collection}

An external data provider conducted interviews with a sample of 540 managers (marketing manager, logistics manager, financial manager, or other) between July and September 2012. The interviews were conducted as CAWI (Computer Aided Web Interview), which means that respondents were recruited by phone and completed the interview online. Only main company units were included in the sample to avoid larger fashion chains to be represented more than once. After conducting the interviews, the data provider removed 48 respondents from the survey as they did not work in the fashion industry. In total, the analysis is based on 492 completed interviews which equates to a response rate of $31.4 \%$.

With regard to the profile of the respondents, the majority (78\%) represented small companies of 1-4 employees. The sample profile represents the fashion industry in general which is characterised by a few major brands and a large number of smaller players. Moreover, due to the global outsourcing of the clothing and textile industry, $71 \%$ of the respondents are involved in fashion retail compared to $17 \%$ in fashion manufacturing. $18 \%$ of the respondents are engaged in fashion design whereas $17 \%$ of the companies are fashion wholesalers. Last, the 
majority of companies deal with women's wear (58\%) and/or men's wear (43\%) whereas only a smaller group of companies are in the market for children's wear (17\%) and outdoor/sport $(17 \%)$.

\section{Measurement of variables}

To date, there have only been few attempts to empirically map dominant business models within an industry, country, or region. An exception is Zott and Amit $(2007,2008)$ who have developed a framework for measuring efficiency-centered and novelty-centered business models. Their work later inspired Brettel et al. (2012) to develop a survey instrument that was tested among small- and medium-sized enterprises (SMEs) in Switzerland, Austria, and Germany. Moreover, Aspara et al. (2010) tested business model innovation and business model replication in a survey among approximately 500 Finnish CEOs and marketing directors. This paper proposes a new model to map business model innovation which is based on Osterwalder and Pigneur's (2010) business model canvas combined with Lindgren and Taran's (2011) distinction between incremental and radical innovation. Business model innovation is considered as a matter of degree rather than an either-or. Instead of aiming for a clear-cut separation between innovative and non-innovative firms, we propose a continuum between exploiting existing competences and exploring new business opportunities. For instance, if a company changes its products, resources, and channels, it will be perceived as more innovative than an organisation which only makes changes in one business model component. More specifically, the respondents are asked if the company's focus is on existing or new activities within each of the nine components 
of the business model canvas: - Value proposition, customer segments, key resources, key activities, key partnerships, customer relationships, channels, cost structure, and revenue streams (see Appendix 1).

Little consensus has emerged on the meaning of corporate sustainability (and related concepts such as corporate social responsibility and corporate citizenship) and multiple measures have been introduced to capture this phenomenon empirically. Instead of adding to the complexity by developing an entirely new scale to measure corporate sustainability, this study uses an adapted version of the items developed by Murillo-Luna et al. (2008, p. 1233-1234). In short, the respondents were asked to what extent they agreed on 10 statements about your company's social and environmental activities? (1=Totally disagree, 10=Totally agree), ranging from corporate sustainability policies to monitoring, reporting, and reward systems (see Appendix 1).

Organisational values also easily escapes precise definition and measurement. At the most general level, values can be defined as "(..) the principles by which both individuals and organisations live" (Sullivan et al., 2002, p. 248). To operationalise the concept, we draw on the work of Prajogo and McDermott (2011) who adopt the competing values framework to distinguish between two types of contrasting cultural orientations relating to structure (flexibility/control) and focus (internal/external). This study emphasises the measurement of the structural dimension of the competing values framework which bears similarities with the work on organic/mechanistic organisational structures (Denison and Spreitzer, 1991). More specifically, respondents were asked to what extent they agree with 16 statements about the behaviour and attitude of people in the organisation (1=Strongly disagree, 3=Neutral, 
5=Strongly agree) (See Appendix 1). The boundaries between the values of the individual owner/manager and the organisational values may in some cases be blurred as the Swedish fashion industry is dominated in numbers by small companies. Poor factor loadings $(<.4)$ implied that three items were subsequently deleted from the analysis (Control and centralization, Routinization, formalization and structure, and Expansion, growth, and development). Therefore, only 13 values items are included in the final analysis.

The measurement of financial performance is based on the respondents' self-reported information on the development in sales, earnings, and market share in the past three years, compared to their closest competitors ( $1=$ Much worse, $10=$ much better). This type of data on self-evaluation of financial performance has been adopted by a number of other scholars (See e.g. Aspara et al. 2010; Menguc et al., 2010).

Size is included as a control variable since corporate sustainability performance is believed to be affected by company size (Jackson \& Apostolakou, 2010). Large companies are more visible in the business landscape, and thus more likely to be in the public limelight, and they have more resources to hire sustainability experts, establish sustainability departments, and develop the technological infrastructure to manage sustainability. In addition, large companies often possess more power in their relationship with suppliers, giving them a better opportunity to address sustainability issues in the different parts of the supply chain. Therefore, it is assumed that corporate sustainability activities on average increase with the size of the company. 


\section{Statistical Analysis and Results}

The hypotheses regarding business model innovation, corporate sustainability, organisational values and financial performance was tested using structural equation modelling (SEM) which allows for the analysis of complex theoretical structures (Mackenzie, 2001). We implemented the nonparametric partial least squares (PLS) regression, developed by Wold (1985), because its minimal requirements for residual distributions, sample size and measurement scales make it highly robust (Hair et al., 2013). Such a model, in contrast to the covariance SEM models, uses a variance-based iterative approach based on multivariate regressions that employ the leastsquares algorithm (Fornell and Cha, 1994). The structural equation modelling technique employs two different model types: (a) a structural model that mirrors the theory-driven hypotheses regarding the associations between the latent variables and (b) measurement models that specify the associations between the latent and the manifest variables. The latent variables reflect the theoretical concepts, while the manifest variables are the observed variables from the surveys. For the analyses, we used the software package SmartPLS (Ringle et al., 2005).

The estimated model is illustrated in Figures 1 and 2. In terms of process, we separated the statistical analysis into two steps. First, we examined the link between business model innovation, corporate sustainability, and financial performance (Figure 1). Second, we added organisational values to the analysis (Figure 2) in order to test whether business model innovation and corporate sustainability can be traced back to deeper organisational structures, focusing on the dichotomy between flexibility and control values. 


\section{Figure 1 about here}

\section{Figure 2 about here}

The quality of the structural and measurement models is evaluated using different criteria. Because structural models are nonparametric, classical inferential statistics cannot be applied. The path coefficients can be interpreted as the standardized coefficients in a traditional regression analysis. For the t-statistics, we calculated the standard errors using nonparametric bootstrapping that treats the original sample as the population and, as recommended for the estimation of standard errors (Efron and Tibshirani, 1993), draws 500 independent random subsamples with replacement (subsample size $=$ original sample size $=492$ ). The reliability of the measurement models is ascertainable using Cronbach's alpha or composite reliability, both of which signal reliability when the value is above .7 (Bagozzi and Baumgartner, 1994). For validity, the average variance extracted (AVE) should be above .5 (Hair et al., 2011), and the factor loading from each manifest variable on its construct must be higher than .4. Discriminant validity is tested by comparing AVE of a latent variable to its largest squared correlation with any other latent variable, and is given if AVE is larger (Fornell and Larcker, 1981). All quality criteria regarding reliability and validity are fulfilled as can be seen in Table 1. 
The statistical analysis document a positive relationship between business model innovation and sustainability (see Figures 3-4 and Table 2). Innovate companies also tend to be more active on the sustainability agenda regardless of whether the organisational values concept is included in the analysis or not (Model 1: $\beta=.200, \mathrm{p}<.001)$, Model 2: $\beta=.105, \mathrm{p}<.01$ ). Therefore, the study provides strong support for Hypothesis 1. In addition, corporate sustainability seems to have a positive impact on financial performance whereas this is not the case for business model innovation. Apparently, fashion companies are not able to reap financial benefits from their innovation efforts. However, in model 1 (Figure 3) the total effect of business model innovation on financial performance is significant $(\beta=.114, \mathrm{p}<.01)$. This result could indicate an interrelationship between sustainability, business model innovation, and financial performance which bears similarities with other recent research results (Busch et al., 2011; Kiron et al., 2013). However, the relationship is no longer significant when organisational values are added into the equation (see Figure 4). Therefore, Hypothesis 3 is only partially supported. The conclusion runs contrary to the notion that business model innovation and corporate sustainability automatically enhance profit. The results instead support previous research which indicates that innovative organisations are not always rewarded by the markets, e.g. due to higher costs, development failures, lack of customer demand, imitation etc. (Simpson et al., 2006).

The inclusion of organisational values into the analysis brings important new insights into the analysis of the linkages between business model innovation, corporate sustainability, and financial performance (see Figure 4). The results show that organisational values are linked to business model innovation $(\beta=.274, \mathrm{p}<.001)$, corporate sustainability $(\beta=.312, \mathrm{p}<.01)$ as well as 
financial performance $((\beta=.249, \mathrm{p}<.01)$. Therefore, the analysis provides support for Hypothesis 2. The results may indicate that organisations characterised by flexibility and discretion are more likely to reap commercial benefits from business model changes and corporate sustainability compared to organisations rooted in values of stability and control. The findings bears similarities with previous innovation research which highlight e.g. organisational culture as a strategic resource that links to both innovation and corporate performance (NaranjoValencia et al., 2011; Prajogo and McDermott, 2011; Surroca et al, 2010). In terms of corporate sustainability, the conclusions are similar to a recent study among financial professionals which concludes that people working in organic organisations (characterised by trust, creativity, openness, collaboration etc.) report higher levels of ethical behaviour, corporate social responsibility, and organisational performance (Jin et al., 2013). Russo and Fouts (1997) also conclude that the relationship between corporate sustainability and economic performance is particularly strong in high-growth industries, which may be caused by the fact that these industries are populated with organisations characterised by flexible structures which facilitates beyond-compliance environmental strategies. In conclusion, a comprehensive transformation is dependent on supportive organisational values which facilitate these changes.

\section{Figure 3 about here}

Figure 4 about here 
Table 2 about here

\section{Discussion: The Limitations of Sustainability Business Model Innovation at the Company Level}

The results from this study indicate that business model innovation, corporate sustainability and financial performance are associated with more deeply rooted values in the organisation. From a managerial perspective, the main lesson from this study is that the execution of business model innovation and corporate sustainability strategies also identifies the need to be working with the values in the organisation. Fundamental changes in the organisation are likely to come to an abrupt halt unless management is able create a climate which facilitates this transformation (see e.g. IBM, 2006, p. 32). The findings from this study provide support to the literature, highlighting soft factors (values and culture) as key for innovation (see e.g. Schlegelmilch et al., 2003; Tellis et al., 2009). Moreover, the study also resonates well with recent research efforts emphasising the values, norms and logics underpinning business models (Randles and Laasch, 2015).

From a broader perspective, however, the question remains if company efforts to develop sustainability through business model innovation are enough to address the fundamental challenges facing an industry, and the economy more generally. Research in sustainability innovation has long stressed the importance of systemic change which goes beyond individual 
company efforts and include multiple actors in different sectors and at different levels (Rohrbeck et al., 2013; Preuss, 2011). As noted by Bocken et al. (2015, p. 67): “(...) collaboration across a wider set of stakeholders in the industrial system is necessary to deliver sustainability. A sustainable society cannot be achieved if individual agents advance their own interests independently". On the contrary, the success of comprehensive sustainability efforts is expected to be dependent on complementary competences and a facilitating infrastructure (Schaltegger et al., 2011; Stubbs and Cocklin, 2008).

The business model concept has been presented as the bridge between company level and system level changes. However, to date the business model literature remains dominated by organisational level analyses and examples. For instance, the literature often lends itself towards illustrative case examples of successful business models, such as Amazon, Dell, Apple, SouthWest Airlines, Gillette, and Wal-Mart (Chesbrough, 2007; Johnson, 2010; Johnson et al., 2008; Lindgardt et al., 2009; Schlegelmilch et al., 2003; Teece, 2010). This organisational level focus also seems to dominate research linking corporate sustainability and business models (Hvass, 2013, 2015; Pedersen and Netter, 2015; Stubbs and Cocklin, 2008). While highlighting the collaborative ties between actors, the business model literature emphasizes the merits of individual firms while focusing less on the context in which these firms are embedded (Stubbs and Cocklin, 2008). Therefore, we are still waiting to see if the concept of business models can bridge company level corporate sustainability and system level sustainability innovation.

The limitations of a company level focus on sustainable business model innovation are visible in the context of fashion. New business models for recycling, upcycling and sharing are still to 
transform the predominant fast fashion business models within the fashion industry (Hvass, 2014, 2015; Pedersen and Netter, 2015). Despite several individual company attempts to address sustainability, the fashion industry continues to have a negative impact on both people and planet (Dickson et al., 2012; Poldner et al., 2011). Some even say that the dominant fashion 'consumption' model (buy 'new', discard 'old') runs contrary to the basic idea of sustainability (Kozlowski et al., 2012). Therefore, we are far from a sustainable fashion industry which: “(...) does not adversely impact people or the planet in its production, manufacture, transport, retail or end of life management" (DEFRA, 2010, p. 5). The lack of progress towards sustainability in the fashion industry can also be seen in other industries. It is increasingly acknowledged that existing approaches to corporate sustainability and corporate social responsibility (CSR) lack speed and scale in order to promote more systemic changes towards sustainability (Visser, 2010). The World Economic Forum (WEF, 2010) argues that current sustainability initiatives fail to challenge the prevalent, and unsustainable models of consumption. Essentially, there needs to be a redefinition of dominant approaches to business. Most industries are still rooted in a linear production system and the "dig it up, use it, throw it away" approach to business makes it difficult to achieve sustainable development in any meaningful way (Wells, 2008, p. 85).

Even companies dedicated to sustainability will find it difficult to become sustainable unless the system surrounding them becomes sustainable as well (Stubbs and Cocklin, 2008). For instance, new collaborative consumption business models (e.g. car sharing) will remain a niche phenomenon unless it is possible to transform the current individualistic, possession-based consumer culture (Botsman and Rogers, 2010; Bardhi and Eckhardt, 2012). Large-scale 
transformations therefore necessitate a systemic perspective that looks at the whole rather than the parts because isolated activities of individual organisations will not fix fundamental flaws in the dominant business system (Johnson and Suskewicz, 2009). It means assessing hard technology, soft organizational changes, dominant systems, and the institutional environment (Ibid., p. 53). In relation to sustainability, the use of natural resources and problems of overconsumption remain key challenges for any meaningful progress toward sustainable development (Birkin et al., 2009, p. 278):

“(...) questions remain as to whether there are still unavoidable structural inhibitions

in contemporary business models that mean that even exemplar corporations that exhibit state-of-the-art environmental management and corporate social responsibility (CSR) may be unable to become sustainable" (Birkin et al. , 2009, p. 278).

\section{Conclusion}

There is a growing literature on the relationship between business model thinking and sustainability (Kiron et al., 2013; Lüdeke-Freund, 2009; Michelini and Fiorentino, 2012; Roome and Louche, 2015; Schaltegger et al, 2015). The purpose of this paper is to contribute to this debate by systematically exploring the relationship between business model innovation and sustainability performance and linking these findings to performance and organisational values. The paper was based on the assumption that certain organisational values underpin business model innovation as well as proactive corporate sustainability strategies. Moreover, both business model innovation and corporate sustainability was expected to be related to financial 
performance, as the ability to make fast changes is seen as an important organizational capability in an increasingly competitive environment. This similarly applies to the fashion industry where the ability to identify and respond to new market trends is key to survival and success.

Survey responses from 492 Swedish fashion companies were used as the empirical basis for testing the relationship between business model innovation, sustainability and underlying organisational values. As hypothesised, fashion companies demonstrating high levels of business model innovation are also more likely to be proactive on the sustainability agenda. The study also shows that organisational values influence all variables in the model: business model innovation, sustainability performance, and financial performance. The findings indicate that the organisational ability to successfully change both business models and sustainability are shaped by the underlying values in the organisation.

The paper has implications for managers. Most importantly, the conclusions from the paper indicate that managers working with corporate sustainability also have to address organisational values. Without this, it will be difficult to bring the organisation beyond a compliance-based approach to corporate sustainability (Russo and Fouts, 1997). The findings thus highlight the importance of avoiding silo-thinking where the planning and implementation of corporate sustainability become a technical exercise detached from more fundamental transformations within the organisation. From a broader perspective, the results show that a corporate sustainability is not only about finding the intersections between corporate goals and 
societal needs. The corporate goals also have to be in sync with more deeply-rooted organisational values.

Likewise, it is concluded that business model innovation is related to the organisational values which indicates that management decisions on business models need to be aligned with the organisational culture. These results may also inspire scholars and practitioners to look more at the actual content of the individual business model components. For instance, the original business model canvas developed by Osterwalder and Pigneur (2010) makes little reference to values when describing the key resources necessary for the business model to work. However, the results from this study indicate that business model innovation is correlated with the cultural assets within the organisation.

Finally, the study has identified a correlation between organisational values and financial performance. These findings indicate that companies characterised by flexibility and discretion perform better than those emphasising stability and order. The scale for organisational values, as used in our interview, (Appendix 1) may not only be a useful measure but also a guide to managers on some of the organisational traits which have to be developed and nurtured in order to be successful in the market place.

The paper of course has limitations. For instance, the paper does not make any claim to have included all variables which potentially mediate the relationship between organisational values, business model innovation, corporate sustainability, and financial performance. Moreover, the analysis only covers companies from a single industry. Evidence indicates that companies operating within the same industry may adopt similar patterns of corporate sustainability 
(Clemens and Douglas, 2005; Jackson and Apostolakou, 2010). In the case of fashion, the industry is also characterised by a myriad of small companies which may have influenced the results. The results may also be influenced by geographical location. At least, there have been talks about a Nordic/Scandinavian sustainability model where companies in general demonstrate relatively high levels of social and environmental performance (Albareda et al., 2007; Gjølberg, 2010). As a recent example, Denmark, Sweden, Finland and Norway are ranked 1-4 on the Global Sustainable Competiveness Index (SolAbility, 2013). Another limitation concerns the explanation of the apparently strong influence of organisational values on business model innovation, corporate sustainability, and organisational performance. While the findings from this study clearly highlight the role of values for value creation, more qualitative, in-depth analyses are needed to better explain how these values are put to work in everyday company processes and practices to promote innovation and sustainability. 


\section{References}

Abdelkafi, N. \& Täuscher, K. (2015). Business Models for Sustainability From a System Dynamics Perspective. Forthcoming in Organization \& Environment.

Accenture, (2010). A New Era of Sustainability: UN Global Compact-Accenture CEO Study 2010, Accenture, 29 November 2010.

Albareda, L., Lozano, J. M., and Ysa, T. (2007). Public Policies on Corporate Social Responsibility: The Role of Governments in Europe. Journal of Business Ethics 74(4), 391-407.

Allwood, J.M., Laursen, S.E., De Rodríguez, C.M., and Bocken, N.M.P. (2006). Well dressed. The present and future sustainability of clothing and textiles in the United Kingdom. University of Cambridge Institute for Manufacturing, Cambridge University.

Amit, R. and Zott, C. (2012). Creating Value Through Business Model Innovation. MIT Sloan Management Review 53(3), 41-49.

Aragón-Correa, J. A., and Sharma, S. (2003). A Contingent Resource-Based View of Proactive Corproate Environmental Strategy. Academy of Management Review 28(1), 71-88.

Ashby, A., Smith, M.H. and Shand, R. (2013). From Principle to Practice: Embedding Sustainability in Clothing Supply Chain Strategies, in: Gardetti, M.A. and Torres, A.L. (Eds.), Sustainability in Fashion and Textiles, Greenleaf Publishing, Sheffield, UK, pp. 61-81.

Aspara, J., Hietanen, J. and Tikkanen, H. (2010). Business Model Innovation vs Replication: Financial Performance Implications of Strategic Emphases. Journal of Strategic Marketing 18(1), 39-56.

Bagozzi, R.P. and Baumgartner, H. (1994). The evaluation of structural equation models and hypothesis testing. In: Bagozzi, R.P. (Ed.). Principles in Marketing Research, Cambridge: Blackwell Publishing, pp. 386-422.

Bardhi, F. and Eckhardt, G.M. (2012). Access-Based Consumption: The Case of Car Sharing. Journal of Consumer Research, 39 (December), 881-898.

Barnes, L. and Lea-Greenwood, G. (2010). Fast fashion in the retail store environment. International Journal of Retail \& Distribution Management 38(10), 760-772.

Birkin, F., Polesie, T. and Lewis, L. (2009). A New Business Model for Sustainable Development: An Exploratory Study Using the Theory of Contstraints in Nordic Organizations. Business Strategy and the Environment 18(277-290. 
Black, S. (2010). Ethical Fashion and Ecofashion. Berg Encyclopedia of World Dress and Fashion, [Online], Volume 10 - Global Perspectives. Available from:

http://www.bergfashionlibrary.com/view/bewdf/BEWDF-v10/EDch10034.xm.

Bocken, N. (2013). Sustainable Business Modelling. http://nancybocken.com/sustainablebusiness-modelling/ Online resource, Posted October 9, 2013 (accessed October 27, 2015).

Bocken, N., Rana, P. and Short, S.W. (2015), Value mapping for sustainable business thinking. Journal of Industrial and Production Engineering 32 (1), 67-81

Bocken, N., Short, S. W., Rana, P. and Evans, S. (2014). A literature and practice review to develop sustainable business model archetypes. Journal of Cleaner Production, 65(15 February 2014), 42-56.

Bocken, N., Short, S., Rana, P. and Evans, S. (2013). A Value Mapping Tool for Sustainable Business Modelling. Corporate Governance 13(5), 482-497.

Boons, F. and Lüdeke-Freund, F. (2013), Business Modes for Sustainable Innovation: State-ofthe-Art and Steps towards a Research Agenda. Journal of Cleaner Production 45, 9-19.

Botsman, R. and Rogers, R., (2010), What's Mine is Yours, Collins, London.

Branco, M. C. and Rodrigues, L. L. (2006). Corporate Social Responsibility and Resource-Based Perspectives. Journal of Business Ethics 69(2), 111-132.

Brettel, M., Strese, S. and Flatten, T. C. (2012). Improving the Performance of Business Models with Relationship Marketing Efforts - An Entrepreneurial Perspective. European Management Journal 30, 85-98.

Busch, T., Stinchfield, B. T. and Wood, M. S. (2011). 'Rethinking Sustainability, Innovation, and Financial Performance', in: Marcus, A., Shrivastava, P., Sharma, S., and Pogutz, S. (Eds), Cross-Sector Leadership for the Green Economy. Palgrave Macmillan, New York, NY, pp. 81105.

Buysse, K. and Verbeke, A. (2003). Proactive Environmental Strategies: A Stakeholder Management Perspective. Strategic Management Journal 24(5), 453-470.

Carroll, A. B. and Shabana, K. M. (2010). The Business Case for Corporate Social Responsibility: A Review of Concepts, Research and Practice. International Journal of Management Reviews 12(1), 85-105.

Casssidy, T.D. and Han, S.L.-C. (2013). Upcycling Fashion for Mass Production, in: Gardetti, M.A. and Torres, A.L. (Eds.), Sustainability in Fashion and Textiles, Greenleaf Publishing, Sheffield, UK, pp. 148-163. 
Charter, M., Gray, C., Clark, T. and Woolman, T. (2008). 'Review: The role of Business in Realising Sustainable Consumption and Production', in: Tukker, A., Charter, M., Vezzoli, C., Stø, E., and Andersen, M. M. (Eds), System Innovation for Sustainability: Perspectives on Radical Changes to Sustainable Consumption and Production. Greenleaf Publishing, Sheffield, UK, pp. 46-69.

Chesbrough, H. (2007). Business model innovation: it's not just about technology anymore. Strategy \& Leadership 35(6), 12-17.

Chesbrough, H. (2010). Business Model Innovation: Opportunities and Barriers. Long Range Planning 43, 354-363.

Christopher, M., Lowson, R., Peck, H. (2004). Creating agile supply chains in the fashion industry. International Journal of Retail \& Distribution Management 32(8), 367-376.

Clemens, B., Douglas, T. (2005). Understanding Strategic Responses to Institutional Pressures. Journal of Business Research 58(9), 1205-1213.

Dahan, N. M., Doh, J. P., Oetzel, J., Yaziji, M. (2010). Corporate-NGO Collaboration: CoCreating New Business Models for Developing Markets. Long Range Planning 43(326-342.

Davenport, T. H., Leibold, M., and Voelpel, S. (2006). Strategic Management in the Innovation Economy, (Publicis Corporate Publishing, Erlangen).

DEFRA (2010). Sustainable Clothing Action Plan (Update Feb 2010), Department for Environment, Food and Rural Affairs, London.

DEFRA (2007). Maximising Reuse and Recycling of UK Clothing and Textiles, Department for Environment, Food and Rural Affairs, London.

Denison, D. R. and Spreitzer, G. M. (1991). Organizational Culture and Organizational Development: A Competing Values Approach. Research in Organizational Change and Development 5, 1-21.

Dickson, M. A., Waters, Y. and López-Gydosh, D. (2012). Stakeholder Expectations for Environmental Performance within the Apparel Industry: The Urgency of Business Response. Journal of Corporate Citizenship 45 (Spring 2012), 37-51.

Efron, B. and Tibshirani, R.J. (1993). An introduction to the bootstrap. Chapman \& Hall, New York.

Fletcher, K. (2008). Sustainable fashion and textiles: design journeys. Earthscan, London.

Fletcher, K., Grose, L. (2012). Fashion \& Sustainability: Design for Change. Laurence King Publishing Ltd., London. 
Fornell, C.G. and Cha, J. (1994). Partial least squares. In: Bagozzi, R.P. (Ed.). Advanced methods of marketing research. Blackwell, Cambridge, pp. 52-78.

Fornell, C.G. and Larcker, D.F. (1981). Two structural equation models with unobservable variables and measurement error. Journal of Marketing Research 18, 39-50.

Giesen, B. (2008). Ethical Clothing - New Awareness or Fading Fashion Trend, VDM Verlag, Saarbrücken, Germany.

Gjølberg, M. (2010). Varieties of corporate social responsibility (CSR): CSR meets the "Nordic Model". Regulation \& Governance 4(2), 203-229.

Haanaes, K., Reeves, M., Velken, I., Audretsch, M., Kiron, D., Kruschwitz, N. (2012). Sustainability Nears a Tipping Point, MIT Sloan Managmeent Review, North Hollywood, CA.

Hair, J.F., Ringle, C.M. and Sarstedt, M. (2013). Editorial: Partial least squares structural equation Modeling: rigorous applications, better results and higher acceptance. Long Range Planning 46, 1-12.

Hair, J.F., Ringle, C.M. and Sarstedt, M. (2011). PLS-SEM: indeed a silver bullet. Journal of Marketing Theory and Practice 19, 139-151.

Hall, J. and Wagner, M. (2012). Integrating Sustainability into Firms' Processes: Performance Effects and the Moderating Role of Business Models and Innovation. Business Strategy and the Environment 21, 183-196.

Halme, M. and Laurila, J. (2009). Philanthropy, Integration or Innovation? Exploring the Financial and Societal Outcomes of Different Types of Corporate Responsibility. Journal of Business Ethics, 84(3), 325-339.

Hamel, G. (2000). Leading the Revolution. Harvard Business School Press, Boston, Massachusetts.

Hanleybrown, F., Kania, J. and Kramer, M. (2012). Channeling Change: Making Collective Impact Work. Stanford Social Innovation Review, 1-8.

Hilger, J. (2008). The apparel industry in West Europe, Copenhagen Business School, Department of Intercultural Communication and Management (ICM), Frederiksberg.

Hvass, K.K. (2015). Business Model Innovation through Second Hand Retailing, Journal of Corporate Citizenship 57 (March 2015), 11-31.

Hvass, K.K. (2014), Post-Retail Responsibility of Garments - A Fashion Industry Perspective, Journal of Fashion Marketing and Management, 18 (4), 413-430. 
IBM (2006). Expanding the Innovation Horizon: Global CEO Study, IBM Business Consulting Services.

Jackson, G. and Apostolakou, A. (2010). Corporate Social Responsibility in Western Europe: An Institutional Mirror or Substitute? Journal of Business Ethics 94, 371-394.

Jin, K. G., Drozdenko, R., and DeLoughy, S. (2013). The Role of Corporate Value Clusters in Ethics, Social Responsibility, and Performance: A Study of Financial Professionals and Implications for the Financial Meltdown. Journal of Business Ethics 112(1), 15-24.

Johnson, M.W. (2009), Seizing the White Space: Business Model Innovation for Growth and Renewal, Harvard Business Press, Boston, Massachusetts.

Johnson, M. W., Christensen, C. M. and Kagermann, H. (2008). Reinventing Your Business Model. Harvard Business Review 86(12), 51-59.

Johnson, M. W. and Suskewicz, J. (2009). How to Jump-Start the Clean-Tech Economy. Harvard Business Review 87(11), 52-60.

Joule, E. (2011). Fashion-forward thinking: Sustainability as a business model at Levi Strauss. Global Business and Organizational Excellence, 30(2), 16-22.

Kania, J. and Kramer, M. (2011). Collective Impact. Stanford Social Innovation Review, Winter 2011, 36-41.

Keskin, D., Diehl, J.C. and Molenaar, N. (2013). Innovation Process of New Ventures by Sustainability. Journal of Cleaner Production 45, 50-60.

Kiron, D., Kruschwitz, N., Reeves, M., Goh, E. (2013). The Benefits of Sustainability-Driven Innovation. MIT Sloan Management Review 54(2), 69-73.

Klewitz, J. \& Hansen, E.G. (2014). Sustainability-Oriented Innovation of SMEs: A Systematic Review, Journal of Cleaner Production 65, 57-75.

Kozlowski, A., Bardecki, M., Searcy, C. (2012). Environmental Impacts in the Fashion Industry: A Life-cycle and Stakeholder Framework. Journal of Corporate Citizenship 45 (Spring 2012), 17-36.

Lee, M.-D. P. (2008). A review of the theories of corporate social responsibility: Its evolutionary parth and the road ahead. International Journal of Management Reviews 10(1), 53-73.

Lindgardt, Z., Reeves, M., Stalk, G. and Deimler, M. S. (2009). Business Model Innovation: When the Game Gets Tough, Change the Game, Boston Consulting Group.

Lindgren, P. and Taran, Y. (2011). A Futuristic Outlook on Business Models and Business Model Innovation in a Future Green Society. Journal of Green Engineering 229-239. 
Lüdeke-Freund, F. (2009). Business Model Concepts in Corporate Sustainability Contexts, Centre for Sustainability Management, Leuphana Universität Lüneburg, Lüneburg, Germany. http://pure.leuphana.de/ws/files/1174317/Luedeke Freund Business Model Concepts in C orp. Sust. Contexts.pdf.

Mackenzie, S.B. (2001). Opportunities for improving consumer research through latent variable structural equation modeling. Journal of Consumer Research 28, 159-166.

Margolis, J. D. and Walsh, J. P. (2003). Misery Loves Companies: Rethinking Social Initiatives by Business. Administrative Science Quarterly 48(2), 268-305.

Medeiros, J.F., Ribeiro, J.L.D., Cortimiglia, M.N. (2014), Success Factors for Environmentally Sustainable Product Innovation: A Systemaic Literature Review, Journal of Cleaner Production, 65, 76-86.

Menguc, B., Auh, S., Ozanne, L. (2010). The Interactive Effect of Internal and External Factors on a Proactive Environmental Strategy and its Influence on a Firm's Performance. Journal of Business Ethics 94, 279-298.

Michelini, L., Fiorentino, D. (2012). New Business Models for Creating Shared Value. Social Responsibility Journal 8(4), 561-577.

Mitchell, D. and Coles, C. (2003). The ultimate competitive advantage of continuing business model innovation. Journal of Business Strategy 24(5), 15-21.

Mitchell, D. W. and Coles, C. B. (2004). Establishing a continuing business model innovation process. Journal of Business Strategy 25(3), 39-49.

Moore, C.M. and Birtwistle, G. (2004). The Burberry business model: creating an international luxury fashion brand. International Journal of Retail \& Distribution Management 32 (8), $412-$ 422.

Morgan, E. (2015). Plan A: Analysing Business Model Innovation for Sustainable Consumption in Mass-Market Clothes Retailing, Journal of Corporate Citizenshop, 57(March 2015), 73-98.

Morris, M., Schindehutte, M. and Allen, J. (2005). The entrepreneur's business model: toward a unified perspective. Journal of Business Research 58(6), 726-735.

Murillo-Luna, J. L., Garcés-Ayerbe, C. and Rivera-Torres, P. (2008). Why do patterns of environmental response differ? A stakeholders' pressure approach. Strategic Management Journal 29(11), 1225-1240.

Naranjo-Valencia, J. C., Jiménez-Jiménz, D., Sanz-Valle, R. (2011). Innovation or imitation? The role of organizational culture. Management Decision 40(1), 55-72. 
Nidumolu, R., Prahalad, C. K. and Rangaswami, M. R. (2009). Why Sustainability is Now the Key Driver of Innovation. Harvard Business Review 87(9), 56-64.

Orlitzky, M. , Schmidt, F.L. and Rynes, S.L. (2003). Corporate Social and Financial Performance: A Meta-Analysis. Organization Studies 24(3), 403-441.

Osterwalder, A. and Pigneur, Y. (2010). Business Model Generation. John Wiley \& Sons, Inc., Hobroken New Jersey.

Pedersen, E.R.G. \& Andersen, K.R. 2015). Sustainability Innovators and Anchor Draggers: A Global Expert Study on Sustainable Fashion, Journal of Fashion Marketing and Management, 19 (3), 315-327.

Pedersen, E. R. G. \& Gwozdz, W. (2014). From Resistance to Opportunity-Seeking: Strategic Responses to Institutional Pressures for Corporate Social Responsibility in the Nordic Fashion Industry. Journal of Business Ethics, 119 (2), 245-264.

Pedersen, E.R.G \& Netter, S. (2015). Collaborative Consumption: Business Model Opportunities and Barriers for Fashion Libraries. Journal of Fashion Marketing and Management, 19(3). 258-273.

Poldner, K., Branzei, O. and Steyaert, C. (2011). Shecopreneuring: Sticthing Global Ecosystems in the Ethical Fashion Industry. In A. Marcus, P. Shrivastava, S. Sharma, and S. Pogutz (eds), Cross-Sector Leadership for the Green Economy, (pp. 157-173). Palgrave Maxmillan, New York, NY.

Prajogo, D. I. and McDermott, C. M. (2011). The relationship between multidimensional organizational culture and performance. International Journal of Operations \& Production Management 31(7), 712-735.

Preuss, L. (2011). Innovative CSR. Journal of Corporate Citizenship 42 (Summer 2011), 17-32.

Randles, S. \& Laasch, O. (2015). Theorising the Normative Business Model. Forthcoming in Organization \& Environment.

Ringle, C.M., Wende, S. and Will, A. (2005). SmartPLS 2.0 (M3) Beta.

Roome, N. and Louche, C. (2015). Journeying Toward Business Models for Sustainability: A Conceptual Model Found Inside the Black Box of Organisational Transformation. Forthcoming in Organization \& Environment.

Rueda-Manzanares, A., Aragón-Correa, J. A. and Sharma, S. (2008). The Influence of Stakeholders on the Environmental Strategy of Service Firms: The Moderating Effects of Complexity, Uncertainty and Munificence. British Journal of Management 19, 185-203. 
Russo, M.V. and Fouts, P.A. (1997). A Resource-Based Perspective on Corporate Environmental Performance and Profitability. Academy of Management Journal 40(3), 534-559.

Santos, J., Spector, B. and Van der Heyden, L. (2009). Toward a theory of business model innovation within incumbent firms. INSEAD, Fontainebleau, France.

Schaltegger, S., Hansen, E.G., Lüdeke-Freund, F. (2015). Business Models for Sustainability: Origins, Present Research, and Future Avenues. Forthcoming in Organization \& Environment.

Schaltegger, S., Lüdeke-Freund, F. and Hansen, E. G. (2012). Business Cases for Sustainability: The Role of Business Model Innovation for Corporate Sustainability. Int. J. Innovation and Sustainable Development 6 (2), 95-119.

Schaltegger, S., Lüdeke-Freund, F. and Hansen, E. G. (2011). Business Cases for Sustainability and the Role of Business Model Innovation - Developing a Conceptual Framework, Centre for Sustainability Management, Leuphana Universität Lüneburg.

Schlegelmilch, B. B., Diamantopoulos, A., and Kreutz, P. (2003). Strategic Innovation: The construct, its drivers and its strategic outcomes. Journal of Strategic Marketing 11, 117-132.

Seelos, C. and Mair, J. (2005). Social entrepreneurship: Creating new business models to serve the poor. Business Horizons 48(3), 241-246.

Seelos, C. and Mair, J. (2007). Profitable Business Models and Market Creation in the Context of Deep Poverty: A Strategic View. Academy of Management Perspectives 21(4), 49-63.

Sharma, S. and Henriques, I. (2005). Stakeholder Influences on Sustainability Practices in the Canadian Forest Products Industry. Strategic Management Journal 26(2), 159-180.

Simpson, P. M., Siguaw, J. A. and Enz, C. A. (2006). Innovation orientation outcomes: The good and the bad. Journal of Business Research 59(113-1141.

Skov, L. (2009). Ethics and the fashion industry in West Europe. Creative Encounters Working Papers \#18, Copenhagen Business School, Frederiksberg.

SolAbility (2013). The Global Sustainable Competitiveness Index 2013. SolAbility, Ilsan, South Korea. http://www.solability.com/pdfs/Sustainable Competitiveness Index Executive Summary.p $\underline{\mathrm{df}}$

Sommer, A. (2012). Managing Green Business Model Transformations. Berlin, Springer.

Sosna, M., Tevinyou-Rodríguez, R.N. \& Velamuri, R. (2010), Business Model Innovation through Trial-and-Error Learning: The Naturhouse Case. Long Range Planning 43, 383-407. 
Spieth, P., Schneckenberg, D., Ricart, J.E. (2014), Business Model Innovation: State of the Art and Future Challenges for the Field, R\&D Management, 44(3), 237-247.

Sullivan, W., Sullivan, R., \& Buffton, B. (2002). Aligning individual and organisational values to support change. Journal of Change Management, 2(3): 247-254.

Stubbs, W. and Cocklin, C. (2008). Conceptualizing a "Sustainability Business Model". Organization \& Environment 21(2), 103-127.

Surroca, J., Tribó, J.A. and Waddock, S. (2010). Corporate Responsibility and Financial Performance: the Role of Intangible Resources. Strategic Management Journal 31, 463-490.

Sustainability (2014). Model Behavior: 20 Business Model Innovations for Sustainability. Sustainability inc., Brooklyn , NY. www.sustainability.com

Teece, D. J. (2010). Business Models, Business Strategy and Innovation. Long Range Planning 43(2-3), 172-194.

Tellis, G.J. (2009). Radical Innovation Across Nations: The Preeminence of Corporate Culture, 73 (January), 3-23.

Visser, W. (2010). The Age of Responsibility: CSR 2.0 and the New DNA of Business. Journal of Business Systems, Governance and Ethics 5(3), 7-22.

Weber, M. (2008). The business case for corporate social responsibility: A company-level measurement approach for CSR. European Management Journal 26(247-261.

WEF (2010). Redesigning Business Value: A Roadmap for Sustainable Consumption, World Economic Forum (WEF), Geneva.

Wells, P. (2008). Alternative business models for a sustainable automotive industry. In: A. Tukker, M. Charter, C. Vezzoli, E. Stø, and M.M. Andersen (Eds), System Innovation for Sustainability I, (pp. 80-98). Greenleaf Publishing Ltd, Sheffield, UK.

Zott, C., Amit, R. and Massa, L. (2011). The Business Model: Recent Developments and Future Research. Journal of Management 37(4), 1019-1042. 


\section{Appendix 1: Survey Questions}

\section{Business Model Innovation}

QUESTION: Over the past three years, how would you assess the strategic focus of your company along the following dimensions:

- $1=$ Focus is on improving EXISTING products and/or services. 10=Focus is on developing radically NEW products and/or services.

- $1=$ Focus is on serving EXISTING markets and customer segments. 10=Focus is on identifying and serving entirely NEW markets and customer segments.

- 1=Focus is on nurturing EXISTING resources and competences (technology, people, IT systems, etc.). 10=Focus is on developing and/or acquiring NEW resources and competences (technology, people, IT systems, etc.).

- 1=Focus is on improving EXISTING core processes and activities (design, logistics, marketing etc.). 10=Focus is on developing NEW core processes and activities (design, logistics, marketing etc.).

- $1=$ Focus is on deepening relationships with EXISTING strategic business partners (suppliers, distributors, end users etc.). 10=Focus is on establishing relationships with NEW strategic business partners (suppliers, distributors, end users etc.).

- $1=$ Focus is on improving EXISTING tools for building customer relationships (personal service, memberships, bonus systems etc.). 10=Focus is on developing NEW tools for building customer relationships (personal service, memberships, bonus systems etc.). 
- $1=$ Focus is on selling products and/or services through EXISTING channels (own stores, partner stores, online, etc.). $10=$ Focus is on selling products and/or services through NEW channels (own stores, partner stores, online, etc).

- $1=$ Focus is on minimizing EXISTING costs incurred when operating the company. $10=$ Focus is on making MAJOR changes in the combination of costs incurred when operating the company.

- $1=$ Focus is on improving sales from EXISTING revenue streams (products, services, leasing, sponsorships etc.). 10=We have developed NEW ways of generating revenue (products, services, leasing, sponsorships etc.).

Source: Osterwalder \& Pigneur combined with Lindgren \& Taran (2011).

\section{Organisational values}

QUESTION: Please assess the extent to which the following statements characterize the behavior and attitude of people in you organsation (1=Strongly disagree, 3=Neutral, 5=Strongly agree):

- Participation, open discussion

- Empowerment of employees to act

- Assessing employee concerns and ideas

- Human relations, teamwork, cohesion

- Flexibility, decentralization

- Expansion, growth, and development

- Innovation and change 
- Creative problem-solving processes

- Control and centralization

- Routinization, formalization and structure

- Stability, continuity, order

- Predictable performance outcomes

- Task focus, accomplishment, goal achievement

- Direction, objective setting, goal clarity

- Efficiency, productivity, profitability

- Outcome excellence, quality

Source: Prajogo \& McDermott (2011)

\section{Corporate Sustainability}

QUESTION: To what extent do you agree with the following statements about your company's social and environmental activities? (1=Totally disagree, 10=Totally agree):

- The company has clearly defined social and environmental objectives.

- The company allocates substantial resources to social and environmental improvements.

- The company regularly measures and reports social and environmental performance.

- The company always tries to substitute polluting materials/products with less polluting ones. 
- Managers and employees receive training and education in social and environmental responsibility.

- Management always considers social and environmental impacts when making important business decisions.

- The company recognizes and rewards managers/employees who contribute to social and environmental improvements.

- The company is open, honest, and transparent in its internal and external communication of social and environmental impacts.

- The company works hard to ensure high social and environmental standards in the supply chain.

- The company actively promotes social and environmental-friendly customer/consumer behaviour.

\section{Financial Performance}

QUESTION: Over the past 3 years, how would you evaluate the financial performance of the company compared to your closest competitors? (1= Much worse, $10=$ much better $)$ :

- Development in sales

- Development in earnings

- Development in market share 